\title{
Elementary Students as Active Agents in their Learning: An Empirical Study of the Connections Between Assessment Practices and Student Metacognition
}

\author{
Heather Braund \& Christopher DeLuca \\ Faculty of Education, Queen's University, Kingston, Canada
}

Full Citation:

Bruand, H., \& DeLuca, C. (2018). Elementary Students as Active Agents in their Learning: An Empirical Study of the Connections Between Assessment Practices and Student Metacognition. Australian Educational Researcher, 45(1), 65-85.
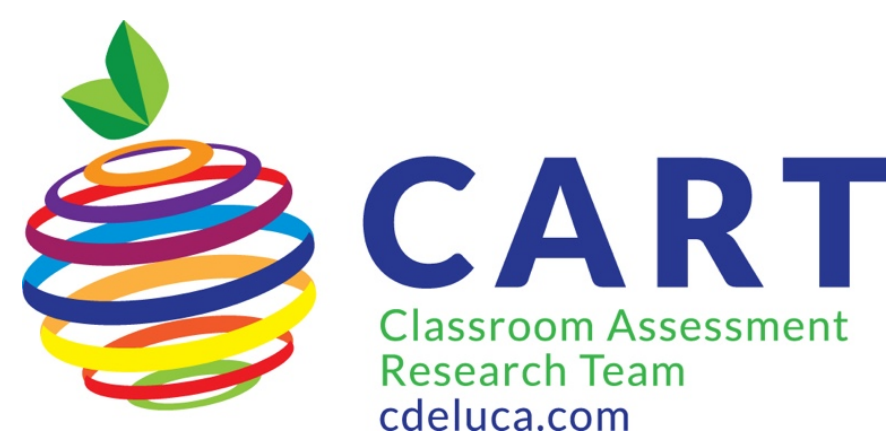

Contact:

Christopher DeLuca cdeluca@queensu.ca @ChrisDeLuca20 


\begin{abstract}
This study explored how elementary teachers leveraged and structured student-involved formative assessment to promote metacognition and self-regulation. Research has suggested a connection between formative assessment practices (e.g. self-assessment and peer-assessment) and metacognition. However, this connection has limited empirical support, especially within early elementary contexts (i.e., grades K-4). In this study, 44 Ontario elementary teachers completed a survey reporting their teaching and assessment practices and beliefs about metacognition. Five participants were then purposefully selected for semi-structured interviews to describe their experiences developing students' metacognition and self-regulatory capabilities through student-involved assessment processes. Data were inductively and thematically analyzed. Participants emphasized the value of assessment as learning practices (e.g. selfassessment and reflective thinking) to develop students' metacognition and discussed the need for ongoing student feedback regarding metacognitive strategies. However, despite purposefully implementing formative assessment to enhance metacognition and self-regulation, participants articulated the need for additional resources to support the cultural shift towards assessment for and as learning within their classrooms.
\end{abstract}

Keywords: classroom assessment, metacognition, elementary education, formative assessment, student agency, self-regulation, assessment for learning, assessment as learning 
Developing students' self-regulatory and metacognitive abilities has been proven to be one of the most significant influences on student learning and academic success (Bingham, Holbrook \& Meyers 2010; Black \& Wiliam 2009; Hudesman, Crosby, Flugman, Isaac, Everson \& Clay 2013). Metacognition is the control and awareness of one's thinking (Baker 2010), whereas self-regulated learning (SRL) is when individuals are able to independently plan, monitor, and assess their learning (Zimmerman 2002). Students self-regulate when they control and monitor their learning through metacognitive behaviours (Pintrich \& Zusho 2002). Students with strong metacognitive behaviours are successful because they understand strategies for effective learning (Wilson \& Bai 2010). Scholars have recognized that formative assessment strategies have the potential to engage students as active agents of their own learning and support SRL and metacognitive behaviours. Specifically, assessment-based activities, such as self- and peer-assessment, goal setting, and reflection are thought to increase students' metacognition (Black et al. 2009; Clark 2012).

Previous research has demonstrated that students benefit from explicit instruction on metacognition and SRL behaviours (Efklides 2006; Flavell 1979; 1987). Moreover, Hattie and Timperley (2007), note that teacher feedback can be purposefully targeted to provoke metacognitive and SRL in students. However, this type of feedback and related assessments are presently not as common within classrooms (Airasian 1997; Hattie \& Timperley 2007). There is an empirical need to investigate how teachers could improve their approaches to assessments for enhancing metacognition and SRL (Earl 2013). Furthermore, while some research has explored the connections between assessment and metacognition in mathematics within older student populations, (Hudesman et al. 2013; Wylie \& Lyon 2015) there is little work conducted in elementary science contexts (Thomas 2011; Zohar \& Barzilai 2013). 
This research explored teachers' explicit use of assessment practices aimed at enhancing students' metacognitive and SRL abilities in elementary science contexts. The following research questions guided this study:

1. What are elementary teachers' beliefs about the role that assessment plays in promoting students' metacognitive thinking?

2. How do teachers use assessment practices to support the development of students' metacognition and self-regulation in their classrooms?

3. What resources and supports would enable teachers to better use assessments to promote students' metacognition and self-regulatory behaviours?

\section{Conceptualizing Metacognition and Self-Regulated Learning}

Metacognition has three main components: metacognitive knowledge, metacognitive regulation, and metacognitive experiences. Metacognitive knowledge (MK) includes the thoughts and beliefs about an individual's cognitive capabilities; it is the general knowledge about one's own cognition (Efklides 2006; Flavell 1979). Metacognitive knowledge is essential for rich learning; students with broad metacognitive knowledge have enhanced SRL behaviours. Metacognitive regulation (MR) is the monitoring, and control of an individual's learning (Flavell 1979). Metacognitive experiences, are the judgments and feelings that people have about their learning (Ben-David \& Orion 2013; Efklides 2006). These experiences could be instances of uncertainty when a student is completing a test, for example, leading the student to asking for clarification. Metacognitive experiences can also manifest as feelings of familiarity or confidence, or difficulty (Efklides 2006). These experiences prompt students to make active changes while learning, such as switching to a more effective strategy (Efklides 2006). All three components of metacognition are important for student success; students must be taught 
explicitly how to develop their metacognition (Kuhn 2000; Moseley et al. 2005). Within the classroom, teachers can leverage all components of metacognition to structure activities that are developmentally appropriate for elementary students (Meusen-Beekman, Brinke \&Boshuizen 2015; Schneider 2008; Spruce \& Bol 2014; Zohar \& Peled 2008). Papleontiou-Louca (2003) provides practical examples for the planning of teaching and learning opportunities that support developing students' metacognition. For example, she suggests prompting students to plan and monitor their own learning, from the beginning (i.e., what students know and don't know prior to beginning a task) to the end of a learning period, with consideration for student-generated learning plans.

Self-regulated learning relates to the capacity to control one's learning and develop knowledge surrounding their learning environment. Self-regulated learning behaviours can be demonstrated through the ability to set goals, determine and use appropriate strategies to meet goals, and monitor learning progress (Schunk 1996). Planning, monitoring, and strategy-use are key components of metacognition and SRL. Self-regulated learning can be conceptualized as having three main phases: forethought, performance control, and the self-reflection. The forethought phase consists of all processes that work towards executing planned actions (e.g. planning goals). The performance control phase includes any actions throughout the learning process (e.g. self-control and use of strategies). The self-reflection phase consists of any reflective and evaluative thoughts that an individual has regarding their performance at the end of a learning period (Schunk \& Zimmerman 2006; Zimmerman 1989, 2000). Self-regulated learning and metacognition are closely linked as metacognitive processes are required for students to be able to engage in self-regulated learning. Therefore, these skills need to be developed together for best results (Zimmerman 2002). 
Connecting Assessment and Metacognition

\section{Conceptualizing Formative Assessment}

Formative assessment was originally identified as the process of using assessment throughout teaching periods to support student learning (Bloom 1969; Scriven 1967). In contrast to summative forms of assessment, formative assessment is non-graded and used to provide feedback to teachers and students about learner progress towards expectations (Black et al. 2009). As conceptions of formative assessment have evolved, they have expanded from a focus on teachers' use of formative information to guide teaching practice to students becoming agentic in the use of assessment information (and practices) to support their own growth and development towards learning standards. A key component of formative assessment is the involvement of feedback directed to students to help them improve their learning and the active participation of students in the construction and use of assessment information to support their own learning (Black et al. 2009). Students require feedback through formative assessment to help them develop metacognitive and SRL behaviours. Students can use feedback to understand their next steps and work towards their goals (Black et al. 2009; Heritage 2010). For example, these changes could include using a different learning strategy, seeking alignment between their planning and pre-determined goals. By integrating feedback from their teacher, peers, and their own self-evaluations students are able to make necessary changes (Black et al. 2009; Heritage 2010).

Students are typically active agents throughout the learning process when contemporary formative assessment practices are used (Clark 2012; Willis 1993). Specifically, current understandings of formative assessment are often described through the dual purposes of: assessment for learning (AfL) and assessment as learning (AaL). AfL is the ongoing process of collecting evidence on student learning with the aim of enhancing student learning. For this 
process to be most beneficial for students, they must be actively involved (Assessment Reform Group 2002). $A a L$ is the process in which students evaluate and reflect upon their learning with the primary purpose of supporting metacognition and SRL development (Earl 2013). AaL can be conceptualized as a subcomponent of the $A f L$ process (Earl 2013). To date, researchers have provided a theoretical link between metacognition and assessment with repeated calls for empirical studies (Baas, Castelijns, Vermeulen, Martens \& Segers 2015; Bingham et al. 2010).

$A a L$ is the deliberate process of encouraging students to develop efficacious and agentic strategies to plan, monitor, and evaluate their learning (Earl 2013). Research posits that $A a L$ encourages student agency and empowers students to take control of their own individual learning process and progress by engaging them in self-monitoring (Earl 2013). Through AaL, students not only enhance their learning of content expectations but more importantly develop skills associated with metacognition and SRL; specifically, self-assessment, goal-setting, reflective thinking, and planning for learning (Dann 2014; Earl 2013).

\section{Connecting Formative Assessment and Metacognition}

Formative assessment practices have been linked to increased student achievement and can be used to develop students' metacognition and SRL (Hudesman, et al. 2013; Ross 2006; Wiliam, Lee, Harrison \& Black 2004). There is a direct connection between SRL and formative assessment (Meusen-Beekman et al., 2015). Clark (2012) reiterates the importance of using formative assessment to promote students' metacognition and SRL behaviours. More specifically, Clark (2012) emphasizes the need for formative assessment to be conceptualized as a process that helps students to develop learning strategies which in turn enhance their learning. Clark elaborates further on formative assessment (p. 217, 2012).

Instead it is designed to continuously support teaching and learning by emphasizing the meta-cognitive skills and learning contexts required for SRL; 
planning, monitoring and...reflection on learning, which both students and teachers use collaboratively to guide further learning and improve performance outcomes.

Zimmerman $(2002,2006)$ cogently emphasized the linked processes of feedback and selfregulation. SRL can be conceptualized as having three fundamental phases in which feedback is a driving force: forethought, performance control, and self-reflection. The forethought phase includes any processes that result in the execution of planned actions (e.g. planning goals). Teachers can work to provide suggestions for how students can plan their work (such as providing a template) before starting their learning. The performance control phase includes any actions throughout the learning process (e.g. use of strategies). Similarly, teachers can provide direct feedback related to students' use of strategies to help them improve their control capabilities. Further, the feedback could also be in the form of suggesting new strategies for students to try. Lastly, the self-reflection phase involves the student's capacity to critically evaluate their learning. Teachers can also provide students with feedback describing how they can evaluate their work using success criteria or expectations.

All three phases are crucial to the learning process for students at any age from Kindergarten to adult learning. Initially it may seem like SRL is primarily a concern when planning for instruction however, it also needs to be considered when planning classroom assessment (Nicol \& Macfarlane-Dick 2006). Feedback from teachers inform the way in which students assess themselves. Further, students must understand their learning gaps before knowing how to address them. Self-assessments are a crucial way to encourage students to reflect on their learning needs. Self-assessments are inherently metacognitive in nature and can help students to recognize their strengths and needs. Self-assessments used in a formative nature can help 
Connecting Assessment and Metacognition

learners to address their gaps and develop a better understanding of where their learning is in relation to the learning goal (Sadler 1989).

\section{The Key Role of Feedback}

To maximize learning, students need to be able to identify and close gaps between what they know and what they need to know (i.e., learning goal) (Ehrlinger, Mitchum \& Dweck, 2016). Feedback can be defined as specific comments directed towards helping students achieve the desired learning goal (Stiggins 2005). Since young children have demonstrated metacognitive thinking (Bronson 2000; Martin, Polly \& Kissel 2017; Whitebread, Coltman, Jameson \& Lander 2009), SRL (King 2003; Neitzel \& Connor 2017) and the ability to recognize feedback (Labuhnm Zimmerman \& Hasselhorn 2010) it can be proposed that these processes are not too complex for young students. Further, it is argued that all learners benefit from a variety of feedback types and support. Students of all ages need to be encouraged to evaluate their learning and generate next steps to help advance their understanding (Tunstall \& Gipps 1996).

\section{Method}

Following ethics approval, 44 Ontario elementary teachers (Kindergarten to Grade 8, ages 4-13) were recruited through the Science Teachers' Association of Ontario (STAO) and teaching networks to participate in this sequential explanatory mixed-methods research study (Johnson \& Onwuegbuzie 2004). This research design consisted of two phases with Phase 1 consisting of a primarily quantitative online survey and Phase 2 consisting of qualitative semi-structured interviews.

The survey was developed by the lead researcher with input from their research team. The survey was comprised of both original questions developed by the researchers, as well as modified questions from two previous scales: Teachers' Metacognitive Scale' (Wilson \& Bai 2010) and 
'Self-Regulated Teacher Belief Scale' (Lombaerts et al. 2009). The survey was piloted with a focus group consisting of five graduate students with varying levels of teaching experience and understandings of cognition. Pilot participants completed the survey individually online and then discussed the appropriateness of each question via a focus group with the lead researcher. The piloting procedure resulted in re-organizing the questions and rephrasing of some troublesome questions. The final survey administered online to Ontario teachers consisted of four demographic questions, seven open-ended questions, and 26-Likert-type items. The 26 Likert-type items were scored on a 5-point scale with 1 representing 'strongly disagree' and 5 representing 'strongly agree'. The Chronbach's alpha reliability for the scale was satisfactory at $\alpha=.88$.

During Phase 1, all participating teachers completed an online open-ended survey focused on their beliefs and practices related to metacognition, teaching, and assessment in elementary science classrooms. Participants from Phase 1 that had a foundational knowledge of metacognition, had been teaching for at least three years, and who indicated interest in discussing their assessment practices were invited to participate in semi-structured interviews for Phase $2(n=5)$. The Phase 2 piloting process was conducted using the same method from Phase 1. Based on focus group feedback, revisions were made to interview questions as necessary. The same lead researcher conducted each semi-structured interview ranging from 40 minutes to 3.5 hours. The 3.5 hour interview was in-depth and contained many detailed examples of integrating metacognition. For this reason the lead researcher allowed the interviewee to continue talking as it remained relevant to the study and research questions. Other interviews were still detailed but generally these interviewees tended to have responses ready (except for the participant from the 3.5 interview) since they were all provided with the questions in advance. Demographic information for each interview participant can be found in Table 1. During the interview, teachers 
were asked to describe their assessment practices aimed at enhancing students' metacognition and SRL as well as discuss challenges they encountered.

\section{Data Analyses}

All interviews were audio-recorded and transcribed verbatim. All data were analyzed inductively using a standard thematic analysis approach (Patton 2016). Data from the interviews and open-ended survey questions were coded concurrently using an emergent approach (Charmaz \& Belgrave 2012). Similar and co-occurring codes were grouped together to generate themes. Data analysis was iterative and the two researchers had ongoing dialogues surrounding emerging codes and themes from all qualitative data. The direct quotations used within the results section were selected as both researchers felt they were representative of the themes and provide a glimpse into participants' beliefs and assessment practices aimed at developing students' metacognition. In total, seven overall themes were identified representing 53 codes. A high degree of inter-rater agreement was observed between the two researchers/raters; in the few cases where data were coded differently, the two raters discussed the data until consensus was reached.

\section{INSERT TABLE 1 HERE}

\section{Results}

Results are presented according to the guiding research questions. For the purpose of this paper, the emphasis is on the qualitative data obtained from the seven open-ended survey questions and semi-structured interviews. See Table 2 for a summary of the themes and codes. Interviewee refers to the collective group of participants whom completed semi-structured interviews but generally, interviewees are referred to by their assigned pseudonyms. Respondent is used to indicate anonymous survey responses, and the term participant is used in instances 
where patterns were seen from both interviewees and respondents. 'Participants' does not necessarily capture all interviewees or respondents but rather refers to a general consensus or pattern.

\section{INSERT TABLE 2 HERE}

\section{Research Question 1. What are elementary teachers' beliefs about the role that assessment plays in promoting students' metacognitive thinking?}

Generally, participants conceptualized metacognition as a process where an individual has the ability to understand and regulate their thinking and learning. Part of being able to understand their thinking is reflecting on their strengths and needs. All interviewees and ten survey respondents also discussed the importance of using learning strategies as part of metacognition. When participants were describing metacognition, they focused on metacognitive knowledge and metacognitive regulation. There was an evident gap in their knowledge of metacognition considering not one participant discussed metacognitive experiences. One respondent provided a conceptualization of metacognition which was well-aligned with literature in the field:

We want our students to be learners who reflect on their learning processes, have awareness of their strengths, needs, and interests and are confident developing a plan for tackling challenging work. Students who are mindful of their own personal learning experience, and can respond critically to those experiences in order to set, track, and achieve new goals, and consider new strategies in order to feel they can be successful. 
This conceptualization is quite deep and accurate, demonstrating the multiple processes involved when thinking metacognitively. More specifically, all three components of metacognition are referenced in the above quote and can be developed through formative assessment practices. Metacognitive experiences is mentioned in terms of having students feeling confident and learning from experiences. Metacognitive regulation is referenced through the act of having students plan and monitor their learning. Lastly, metacognitive knowledge is mentioned in the above quote through having students be aware of their strengths and needs.

Three themes were identified in response to the research question investigating teachers' beliefs about the role that assessment plays in promoting metacognitive thinking: (a) student reflection, (b) assessment for teacher learning, and (c) assessment as learning techniques. Participants continually highlighted student reflection as a major component of metacognitive thinking, and as the visible action associated with metacognitive behaviour. For example, a respondent explained how they integrated metacognition, "asking students to reflect on the strengths and weaknesses of their science experiments and engage in inquiry projects which challenge them to be metacognitive scientists who engage in ongoing reflection and reworking of their design plans, research, and experiments." Teachers emphasized the need for reflection to be ongoing throughout the learning period. Despite participants conceptualizing reflection as a key component of metacognition, they did not use the terms interchangeably. Further, metacognition was considered to encompass more than reflective thinking.

Some strategies to integrate reflective thinking into lessons were planning for reflection within daily plans and engaging in "guided reflection," providing a structure for reflection rather than a generic or open form of reflection (Respondent). Similarly, Anna described a way in which students reflected in her classroom, "they'll often reflect back on what they were thinking 
at different steps along the way. Did they change how they were designing or problem-solving with new information? Were they aware of what they were thinking?" Similarly, Jacob described the importance of reflective thinking, "it cements some of the learning for sure. I try to uncover for them what was new that they learned. What did they already know? What was interesting? What's something that they might pursue more? So, a good check in at the end of a project is a useful exercise for sure. I think it works.” Strategic questioning was frequently used to encourage student reflection as a foundation for metacognitive regulation and metacognitive knowledge.

A second theme, assessment for teacher learning, was observed as a way for teachers to alter their practices to better support students' metacognitive development. David discussed the need for mutual feedback, "Yeah so you're asking me feedback for the kids right? See my answer is that it is both ways. That I need the feedback for me to be able to give them the feedback." This quote demonstrates how David seeks feedback from his students that informs his teaching practices and feedback. Further, he describes the need for mutual feedback, "It has to be. If it's not then you're a dictator and you are not being democratic." Several teachers explicitly conceptualized feedback as a two-way process where they were just as anxious (and excited) to receive feedback from their students as they were to provide feedback. This two-way feedback process can help teachers to tailor their instruction to meet students' needs while also helping students to advocate for their needs through knowledge of their thinking (metacognitive knowledge). Participants discussed how they documented student learning which clearly prompted them to reflect upon how they can modify their practices to better support students. Similarly, a respondent explained, "by knowing their learning processes, students can then share this information with their teachers who can then make sure that they model their lessons to include these processes." In this way, teachers can model metacognitive and SRL behaviours that 
students need to learn through observing. By having students understand their learning processes and share with their teachers, students are provided with opportunities to demonstrate selfregulated learning behaviours such as: using learning strategies effectively and evaluating the extent to which they meet pre-determined learning goals.

AaL techniques were frequently described as necessary components of metacognitive thinking. These techniques included the use of success criteria, providing descriptive and ongoing feedback for students, peer-assessment, self-assessment, conferencing, portfolios, and reflective thinking all aimed at supporting students metacognitive and SRL behaviours. Participants always discussed metacognition alongside these assessment techniques. This result suggests that participants conceptualize AaL techniques as necessary for effective metacognitive thinking.

The use of conferencing was discussed by two interview participants as means of assessing student understanding and encouraging metacognition. Conferencing was also seen as an opportunity for students to reflect on graded work and discuss next steps. Amanda discussed this approach, 'So it's ongoing. I will pull kids aside and say, 'how do you think that went?' And you always have to build up that relationship and that rapport so that kids will be like 'holy cow, I had no idea..."”. Conferencing was a way in which Amanda worked to build a safe classroom environment with her students so that they felt comfortable discussing their struggles. This is an approach that can help students to understand and act on their metacognitive experiences. Further, conferencing used in this way could help students articulate their thinking and reveal their thought processes.

Similarly, David describes how he used conferencing to support student learning and metacognition: 
So traditionally people do it at the beginning of the year for the first report card or progress report... So that's where all work comes in, the kids spend time writing up reflective pieces, very very short, on each piece of work that they're doing and then they take those and they turn them into you know like a 1-2 pager which they're going to read to their parents on the day of the conference. And then the teacher facilitates with the student, right. So, the student acknowledges their learning and how they do that. So that's one thing that I do, I have kids like physically write down and reflect on their work.

This quotation shows the way in which David used student-led conferences for $A a L$ purposes to encourage reflective thinking and metacognitive behaviours. More specifically, the reflective thinking described by David is part of the self-reflective phase of self-regulated learning and a foundation for metacognitive regulation.

Many of the $A a L$ practices were relatively simple for the teachers to implement. Anna described how she used a checklist to encourage students to engage in self-assessment thus allowing them the opportunity to practice and develop their self-appraisal skills. The checklist technique was one of the many tools that Anna used to help her students engage in metacognitive thinking. The checklist was also paired with other techniques such as questioning and reflective thinking. Similarly, the other participants also discussed a wide variety of tools and practices that they used together to encourage the development of their students' metacognitive thinking. This result suggests that participants from this study generally conceptualized the development of metacognition as requiring a variety of tools hinting at the complex nature of the construct.

Further, the majority of participants discussed the importance of providing direct feedback to students, which helped them to develop their metacognition. Feedback was one of the most 
common practices across all teachers. Anna described how she provided feedback on an assessment of learning $(A o L)$ task, "I do things for myself like I'll do little quizzes and then give them feedback to where they are for themselves to self-monitor." This self-monitoring piece is a key component of metacognitive thinking.

Participants also described how they provided feedback as students progressed through the unit of study rather than at the end of the learning period. Many teachers agreed that providing students with feedback was beneficial. The need for specific, descriptive, and timely feedback was discussed by interviewees. Participants discussed how feedback can be both informal and formal. Anna talked about how she interacts with students to provide more informal feedback. "Yes if they're building something or if they're also just working individually then I can walk around and just give some oral feedback or trying to see what's not working." So in this instance Anna was both providing feedback but also collecting feedback from the students so that she could determine what wasn't working well for them. Anna was also providing students with opportunities to demonstrate their metacognitive knowledge and self-regulatory behaviours.

The interviewees discussed how they were not the only sources of feedback for their students. They worked to encourage their students to provide peer-feedback. These results demonstrated that participants were very focused on providing students with feedback from a multitude of sources (self, peer, and teacher) to help encourage metacognition. Further, many strategies that they discussed in their classes incorporated formative assessment. Teachers recognized the role that $A o L$ had in their classrooms and understood the need for summative assessments; however, these results suggest a shift towards a more formative assessment orientation within these classrooms when teachers consider the development and growth of students' metacognitive thinking. 


\section{Research Question 2: How do teachers use assessment practices to support the development of students' metacognition and self-regulation in their classrooms?}

Data from the survey and interview provided two dominant themes in response to this research question: (a) dialogic assessment, and (b) defining success and helping students understand what constitutes successful work. Dialogic assessment refers to opportunities for students to exchange ideas about where they are in their learning and where they need to go including strategies to get there. Dialogic forms of assessment include both peer-, teacher-, and self-referenced exchanges as students in all cases are able to critically reflect on their learning and learning strategies (i.e., via internal or external dialogues). All teachers saw self- and peerassessment as deliberate ways to promote students' metacognitive thinking. The use of selfassessment was linked to critical thinking and developing self-appraisal skills and "seen in every subject" (Jacob). The use of peer-assessment also complimented the ongoing emphasis from all interviews on the need to encourage dialogue in their classrooms, regardless of the grade levels they were teaching. Instances where students were engaging in dialogue with their peers sometimes resulted in more informal stances of peer-assessment where students were providing ongoing feedback through dialogue. Peer- and self-assessment processes were built upon the creation of a dialogic classroom culture supported by success criteria and explicit learning expectations that ideally were "developed and shared with students before the learning process begins" (Jacob). Self- and peer assessments are dialogic in nature when results from the assessments are discussed with the teacher and peers. Peer-assessment is helpful for students because it encourages them to focus on specific criteria and consider their peers' achievement in 
relation to the same standards that they are working toward. As students are determining the extent to which their peers have met specific learning goals, they simultaneously reflect on their own performance and come to better understand the learning expectations. Therefore, students are engaging in metacognitive thinking as a result of peer-assessment (Fisher, 2013).

Participants also described a variety of ways to design self and peer-assessments such as: the use of rubrics, checklists, prompting questions, and Google Forms. Notable was the formative use of these strategies during learning periods but also summatively during evaluative periods. Hence the same assessment formats were used continuously to connect formative experience with summative experiences of assessment. Anna in particular described how she noticed a difference in the quality of work by using self- and peer-assessment tools to prompt metacognitive regulation continuously in her classroom: "I do find that with peer-assessment and self-assessment before they hand in any work then the quality definitely is better. Because they have another chance to self-correct themselves." A few participants also discussed how students self-assessed their work through rubrics, such as having students assess themselves before completing an oral presentation. The teacher would utilize the same rubric when grading the students so that the criteria were consistent.

The next theme, defining success and helping students understand what constitutes successful work, involves using success criteria to articulate and engage students in reflective thinking on their learning processes and products. Success criteria (i.e. the criteria that are required for a student to be successful at a learning task), "provide the basis that enable students to be metacognitive" (Ben). Without success criteria, students are unable to reflect on where they are and where they need to go to improve their learning and work. The use of success criteria can promote metacognitive goal-setting. Further, students utilize success criteria metacognitively 
Connecting Assessment and Metacognition

when they are 'monitoring' their learning and 'evaluating' the extent to which they have met the criteria.

Participants described the need to promote the use of success criteria with their students across grades. Amanda talked about how she wanted her students to have the success criteria right in front of them all the time, "so that they can physically check it off because normally I'll refer to it...point to it right, what do you think that you've totally mastered and what's your next step? Where do you have to go next with your learning?" This quote shows how Amanda encouraged her students to monitor their learning through the use of success criteria. Similarly, when survey respondents were asked to 'describe how you integrate metacognition when you teach science’ one respondent described, “we just completed our Grade 5 Energy Inquiry Projects where each student selected their own question/topic...We created the success criteria as a class..." However, success criteria were not always co-constructed with their students, there were instances where teachers constructed criteria in advance and provided them to students, a common practice in schools. When constructing success criteria, the need for student-friendly language was discussed as described by Ben, "Of course, success criteria only work when students understand them. So it is important for the language to be at their level, and for you to spend some time making sure students understand the criteria before they do their self- or peerassessments".

Participants also emphasized the need to use learning goals alongside their success criteria. Learning goals differ from success criteria in the Ontario context as learning goals state what students should know or be able to do and success criteria describe what successful learning of the goal looks like. When teachers were asked 'how do you help students plan their learning?’ David responded by saying, “...it's your learning intention, success criteria but 
basically in my mind it's allowing them to know where we're starting, what we're kind of going to be doing and where we're going." Here David emphasized the need for students to know learning goals and success criteria before starting their learning, so that they incorporated it into their planning processes. Students were set up for success as they understood their learning goals and success criteria. Further, students monitored their learning through checking their progress in relation to success criteria and learning goals.

Success criteria were used in the primary grades as well. Ben, a Kindergarten teacher discussed how he co-constructed success criteria with his students: "so they learn from each other and then so okay should we put down criteria? What makes boats float? ... Up it goes and then I'd model for them, 'hey look I know so and so is using that chart'...”. Using success criteria was also seen as a strategy that could be used to help engage students and provide them with responsibility for their learning. It is evident from the interview data that students still needed reminding about the use of success criteria, that it has yet to become a fully integrated pedagogy across classrooms. Further, participants reported that they worked to provide visual prompts and examples of success criteria, they encouraged the students to check their progress using the success criteria to help develop their metacognitive regulation, monitoring, and evaluation skills. When teachers encouraged their students to monitor their progress using success criteria, the process helped students think about their thinking and the extent to which they met their learning goals.

\section{Research Question 3: What resources and supports would enable teachers to better use assessments to promote students' metacognition and self-regulatory behaviours?}


Teachers in this study indicated that they struggle to implement strategies that supported development in students' metacognition and SRL, with this struggle noted not only in science but across subjects. Two themes emerged to help support teachers in this area: (a) explicit professional development opportunities and sharing of relevant resources, and (b) concrete metacognitive and assessment resources. Amanda talked about how she and her colleagues had to pick a sample of work from a student in their classrooms and demonstrate how they had worked to move the student forward as part of their staff meetings. She discussed the encouraging nature of these meetings and emphasized the benefits of seeing ways in which teachers supported their students.

Participants discussed specific examples and issues they faced in using assessment and pedagogy to enhance students' metacognition and SRL. For example, several teachers articulated the challenge of documenting their students' learning in authentic and ongoing ways whilst attending to all students' needs. Feedback was frequently integrated into the ongoing discussions around supporting students' metacognition in the classroom, and yet teachers struggled to find ways to provide and document meaningful feedback.

Participants also voiced the need for "a variety of different practices rather than just selfreflection" (Respondent). Further, participants are seeking a curriculum that values both formative assessment and metacognition, shifting away from the traditional approach to assessment. In some instances, participants described ways in which the science curriculum was a barrier for them when integrating metacognition. A respondent suggested, "I think the Ontario science curriculum needs to be revamped in the way the social studies curriculum was, so there is more focus on inquiry. I find with memorizing facts there is less opportunity for self-reflection, and I find students are better able to reflect when their learning is more self-directed." Lastly, other 
limitations reported by participants were lack of time to provide feedback, time to plan and integrate metacognition while meeting all curricular expectations, and issues with class sizes as it was difficult to observe all students regularly.

Given the expressed challenges related to assessment, participants repeatedly called for concrete resources in metacognition and assessment. Teachers recognized that these resources could come from other educators as they discussed the role that their colleagues could play in sharing resources and strategies for enhanced teaching and learning of metacognition and SRL. One survey respondent elaborated, "I have recently found that working with other teachers and having the students engaged in cross-curricular tasks/assignment/projects can very much assist in allowing for engagement in metacognitive activities." Having teachers share the resources that work well for them when integrating metacognition but also discuss their formative assessment practices aimed at students' metacognitive development could reduce some of these challenges.

\section{Discussion}

Previous research has suggested the need for teachers to provide students with direct instruction on metacognition and SRL (Efklides 2006; Flavell 1979; 1987). Further, Hattie and Timperley (2007) outlined the need for teacher feedback to be tailored to promoting students' metacognition and SRL. However, feedback and assessments typically lack suggestions for what students can do as active agents within the assessment process to increase their metacognition and SRL (Airasian 1997; Hattie \& Timperley 2007). Furthermore, empirical evidence on how teachers can use their assessment practices to develop students' metacognition and SRL is sparse (Earl 2013), particularly in elementary and science contexts (Zohar et al. 2013). Therefore, this study aimed to explore teachers' assessment practices with a focus on developing students' 
metacognition and SRL. One recognized limitation of this study is the small sample size. Despite the small sample size, we reached data saturation in the interviews and survey. We also understand that some data may be unique to our context of Ontario, however given the movement towards a more formative approach to assessment we hope that our findings can benefit those within and outside of our context to gain a better understanding of the intersection between metacognition and formative assessment. Further, another limitation is the self-report nature of the data as it only sheds light on teachers' reported actions rather than actual student and teacher behaviours within the classroom.

In this study, teachers viewed all assessment as a primary vehicle to promote metacognition and SRL within their elementary classrooms; in fact, when describing general pedagogies, assessment was repeatedly featured as a consistent strategy to serve this aim. Despite the recognition of how assessment of learning could be used to promote metacognition, the emphasis remained of assessment for learning and assessment as learning practices. Specifically, assessment strategies such as self- and peer- assessments and dialogic assessments were frequently reported. Participants also discussed the need for ongoing formative assessment practices to be used in order to establish patterns of learning in students. This is congruent with Clark's (2012) conceptualization of formative assessment requiring students to be active participants in their learning.

Teachers commented that involving students in the assessment process led them to perceive their students as having greater agency. More specifically, interviewees described instances where students were active in assessment and feedback processes (e.g. self- and peerassessment) while taking ownership of their learning goals, strategies, and plans. The ongoing assessment dialogue discussed by teachers also suggested that students remained active in the 
Connecting Assessment and Metacognition

process while providing peer feedback. Self-assessment and peer-assessment techniques were some of the most frequently mentioned $A a L$ practices across participants. This finding is promising as research has suggested that self-assessment affects student achievement (Bingham et al. 2010; McMillan \& Hearn 2009; Schunk 1996). However, research also suggests that the effectiveness of self-assessment increases when teachers explicitly teach students how to selfassess (Ross, Rolheiser \& Hogaboam-Gray 1999; 2002; Ross, Tronson \& Ritchie 2005). Teachers did not discuss ways in which they directly taught their students how to engage in effective self-assessment. It is also helpful for students to receive feedback on their selfassessments from teachers so that they can better understand discrepancies between their selfassessment, peer-assessments, and teacher assessments (Ross 2006). Teachers in this study did not discuss providing feedback on students' completed self-assessments. Therefore, future research should examine strategies that support teachers' explicit support of self-assessment in elementary classrooms.

AaL was emphasized as a student-agentic approach to promote student metacognition and SRL by teachers in this study. This empirical finding corroborates theoretical assertions that $A a L$ encourages students to purposefully consider their learning strategies, while planning, monitoring, and evaluating their growth towards learning goals (Baas et al. 2015; Dann 2014; Earl 2013). This study demonstrates ways in which teachers can work to engage students in $A a L$ practices, as early as Kindergarten, to promote metacognition. As early primary education is a critical period to promote habits of self-regulation, leveraging $A a L$ as reported in this study is an important empirical contribution to the literature and suggests that not only is it possible to use assessment in this way with early learners, but more importantly, it is a valued a pedagogy by teachers to enhance students' SRL. 
Findings from this study have highlighted that some Ontario elementary teachers reported efforts to promote metacognitive thinking through a variety of $A f L$ and $A a L$ practices. However, despite the work that teachers have discussed to shift the assessment culture in their classrooms towards a more formative stance, it is evident that teachers require further support and resources to help develop students' metacognition. Future scholarship should build on the findings from this study to develop and promote empirically-supported resources and professional development practices that could enhance teachers' practices in this area. In particular, teachers appear to continue to view assessments as activities they do with and to students (i.e., specific tasks; for example, conducting a self-assessment), rather than a pervasive approach to their pedagogy (i.e., a formative assessment orientation to teaching). While these tasks are largely student-centered and can enable moments of student agency (Willis 2010), they remain initiated by teachers and potentially perceived as 'add in' activities rather than the 'modus operandi' for student learning. The next step in the formative assessment path would be to encourage teachers to adopt $A f L$ and $A a L$ as pedagogical approaches - to cultivate an assessment pedagogy (Fleer 2015) - where assessment becomes a fundamental driver of teaching and learning, and where students actively participate in the development and use of classroom assessment criteria and processes. In this way, assessment operates more organically within teaching and learning processes and works authentically as an agentic device to stimulate student engagement and metacognitive learning.

Accordingly, we are left wondering how we might cultivate classroom cultures that inherently value formative assessment as the basis for student-led learning. Based on data from this study, teachers are clearly moving in the right direction. Yet interviewees and respondents continued to identify that they need support integrating assessment in their classrooms, specifically to promote student agency and learning of metacognition. Future research needs to 
Connecting Assessment and Metacognition

address these challenges head-on and find ways to help teachers reconceptualize assessment as an integrated component of pedagogy and learning in which students are given greater ownership in structuring the learning environment if they are to truly take the driver's seat in assessment. 


\section{References}

Airasian, P. W. (1997). Classroom assessment (3rd ed.). New York: McGraw-Hill.

Assessment Reform Group. (2002). Assessment for learning: 10 principles. Port

Melbourne: Cambridge University Press.

Baas, D., Castelijns, J., Vermeulen, M., Martens, R., \& Segers, M. (2015). The relation between Assessment for Learning and elementary students' cognitive and metacognitive strategy use. British Journal of Educational Psychology, 85(1), 33-46.

Baker, L. (2010). Metacognition. In International Encyclopedia of Education (3rd ed, pp. 204210). Oxford, United Kingdom: Elsevier.

Ben-David, A., \& Orion, N. (2013). Teachers' voices on integrating metacognition into science education. International Journal of Science Education, 35, 3161-3193.

Bingham, G., Holbrook, T., \& Meyers, L. E. (2010). Using self-assessments in elementary classrooms. Phi Delta Kappa International, 91(5), 59-61.

Black, P., \& Wiliam, D. (2003). 'In praise of educational research': Formative assessment. British Educational Research Journal, 29, 623-637.

Black, P., \& Wiliam, D. (2009). Developing the theory of formative assessment. Educational Assessment, Evaluation and Accountability, 21(1), 5-31.

Bloom, B.S. (1969). Some theoretical issues relating to educational evaluation. In R. W. Taylor (Ed.), Educational evaluation: New roles, new means: The 68th yearbook of the National Society for the Study of Evaluation, Part II (pp. 26-50). Chicago: University of Chicago Press.

Bronson, M. B. (2000). Self-regulation in early childhood. New York: NY Guilford.

Charmaz, K., \& Belgrave, L. (2012). Qualitative interviewing and grounded theory analysis. The 
SAGE handbook of interview research: The complexity of the craft, 2, 347-365.

Clark, I. (2012). Formative assessment: Assessment is for self- regulated learning. Educational Psychology Review, 24, 205-249.

Dann, R. (2014). Assessment as learning: Blurring the boundaries of assessment and learning for theory, policy and practice. Assessment in Education: Principles, Policy \& Practice, 21(2), 149-166.

Earl, L. M. (2013). Assessment as learning: Using classroom assessment to maximize student learning. Thousand Oaks, CA: Corwin.

Efklides, A. (2006). Metacognition and affect: What can metacognitive experiences tell us about the learning process? Educational Research Review, 1, 3-14.

Ehrlinger, J., Mitchum, A. L., \& Dweck, C. S. (2016). Understanding overconfidence: Theories of intelligence, preferential attention, and distorted self-assessment. Journal of Experimental Social Psychology, 63, 94-100.

Fisher, R. (2013). Creative dialogue: Talk for thinking in the classroom. Routledge.

Flavell, J. H. (1987). Speculations about the nature and development of metacognition. Metacognition, motivation, and understanding, 21-29.

Flavell, J. H. (1979). Metacognition and cognitive monitoring: A new area of cognitivedevelopmental inquiry. American psychologist, 34(10), 906.

Fleer, M. (2015). Developing an assessment pedagogy: the tensions and struggles in retheorising assessment from a cultural-historical perspective. Assessment in Education: Principles, Policy \& Practice, 22(2), 224-246.

Hattie, J., \& Timperley, H. (2007). The power of feedback. Review of Educational Research, $77(1), 81-112$. 
Heritage, M. (2010). Formative assessment and next-generation assessment systems: Are we losing an opportunity? Washington, D.C.: National Center for Research on Evaluation, Standards, and Student Testing and the Council of Chief State School Officers.

Hudesman, B. J., Crosby, S., Flugman, B., Issac, S., Everson, H., \& Clay, D. B. (2013). Using formative assessment and metacognition to improve student achievement. Journal of Developmental Education, 37(1), 2-13.

Johnson, R. B., \& Onwuegbuzie, A. J. (2004). Mixed methods research: A research paradigm whose time has come. Educational Researcher, 33(7), 14-26.

King, M. (2003). The effects of formative assessment on student self-regulation, motivational beliefs, and achievement in elementary science (Unpublished doctoral dissertation). George Mason University, VA.

Kuhn, D. (2000). Theory of mind, metacognition and reasoning: A life-span perspective. In P. Mitchell \& K.J. Riggs (Eds.), Children's Reasoning and the Mind (pp. 30326). Hove, UK: Psychology Press.

Labuhn, A. S., Zimmerman, B. J., \& Hasselhorn, M. (2010). Enhancing students's self-regulation and mathematics performance: the influence of feedback and self-evaluative standards. Metacognition and Learning, 5, 173-194.

Lombaerts, K., Braak, J. Van, \& Athanasou, J. (2009). Development of the self- regulated learning teacher belief scale. European Journal of Psychology of Education, 24, 79-96.

Martin, C., Polly, D., \& Kissel, B. (2017) Exploring the impact of written reflections on learning in the elementary mathematics classroom. The Journal of Educational Research, 110, $538-553$. 
Moseley, D., Baumfield, V., Elliott, J., Gregson, M., Higgins, S., Miller, J., \& Newton, D. P. (2005). Frameworks for thinking: A handbook for teaching and learning. Cambridge, UK: Cambridge University Press.

McMillan, J. H., \& Hearn, J. (2009). Student self-assessment: The key to stronger student motivation and higher achievement. Educational Horizons, 87(April), 39-45.

Meusen-Beekman, K. D., Joosten-ten Brinke, D., \& Boshuizen, H. P. (2015). Developing young adolescents' self-regulation by means of formative assessment: A theoretical perspective. Cogent Education, 2(1), 1071233.

Neitzel, C., \& Connor, L. (2017) Messages From the Milieu: Classroom Instruction and Context Influences on Elementary School Students' Self-Regulated Learning Behaviors, Journal of Research in Childhood Education, 31:4, 548-560.

Nicol, D. J., \& Macfarlane-Dick, D. (2006). Formative assessment and self-regulated learning: A model and seven principles of good feedback practice. Studies in Higher Education, $31,199-218$.

Patton, M. Q. (2016). Qualitative research and evaluation methods: Integrating theory and practice (4th Ed.). Thousand Oaks, CA: Sage.

Papleontiou-Louca, E. (2003). The concept and instruction of metacognition. Teacher Development, 7(1), 9-30.

Pintrich, P. R., \& Zusho, A. (2002). The development of academic self-regulation: The role of cognitive and motivational factors. In A. Wigfield \& J. S. Eccles (Eds.), Development of achievement motivation (pp. 250-284). San Diego: Academic Press.

Ross, J.A. (2006). The reliability, validity, and utility of self-assessment. Practical Assessment, Research, and Evaluation, 11(10), 1-13. 
Ross, J. A., Hogaboam-Gray, A., \& Rolheiser, C. (2002). Self-evaluation in Grade 11 mathematics: Effects on achievement and student beliefs about ability. In D. McDougall (Ed.), OISE papers on mathematical education (pp. 71-86). Toronto, Canada: Ontario Institute for Studies in Education, University of Toronto.

Ross, J. A., Rolheiser, C., \& Hogaboam-Gray, A. (1999). Effects of self-evaluation training on narrative writing. Assessing Writing, 6,107-132.

Ross, P., Tronson, D., \& Ritchie, R. (2005). Modelling photosynthesis to increase conceptual understanding. Journal of Biological Education, 40(2), 84-88.

Sadler, D. R. (1989). Formative assessment and the design of instructional systems. Instructional Science, 18,119-144.

Schneider, W. (2008). The development of metacognitive knowledge in children and adolescents: Major trends and implications for education. Mind, Brain, and Education, 2, 114-121.

Schunk, D. (1996). Goal and self-evaluative influences during children's cognitive skill learning. American Educational Research Journal, 33, 359-82.

Schunk, D. H., \& Zimmerman, B. J. (2006). Competence and control beliefs: Distinguishing the means and ends. In P. A. Alexander \& P. H. Winne (Eds.), Handbook of educational psychology (2nd ed., pp. 349-367). Mahwah, NJ: Erlbaum.

Scriven, M. (1967). The methodology of evaluation. In R. W. Tyler, R. M. Gagne, and M. Scriven (Eds.), Perspectives of curriculum evaluation, Volume I (pp. 39-83). Chicago, IL: Rand McNally.

Spruce, R., \& Bol, L. (2015). Teacher beliefs, knowledge, and practice of self-regulated learning. 
Metacognition and Learning, 10, 245-277.

Stiggins, R. (2005). From formative assessment to assessment FOR learning: Phi Delta Kappan, 87(4), 324-328.

Thomas, G. P. (2011). Metacognition in science education: Past, present and future considerations. In B. J. Fraser, K. G. Tobin, and C. J. McRobbie (Eds.), Second International Handbook of Science Education (pp. 131-144). Dordrecht, NL: Springer.

Tunstall, P. \& Gipps, C. (1996) Feedback and formative assessment: children's perceptions. Paper presented at the Annual Meeting of the American Educational Research Association, New York, NY.

Whitebread, D., Coltman, P., \& Jameson, H. (2009). Play, cognition and self-regulation: What exactly are children learning when they learn through play? Educational \& Child Psychology, 26(2), 40-52.

Wiliam, D., Lee, C., Harrison, C., \& Black, P. (2004). Teachers developing assessment for learning: Impact on student achievement. Assessment in Education: Principles, Policy \& Practice, 11(1), 49-65.

Willis, J. (2010). Assessment for learning as a participative pedagogy. Assessment Matters, 2, $65-84$.

Wilson, N. S., \& Bai, H. (2010). The relationships and impact of teachers' metacognitive knowledge and pedagogical understandings of metacognition. Metacognition Learning, 5, $269-288$.

Zimmerman, B. J. (1989). Academic studying and the development of personal skill: A selfregulatory perspective. Educational Psychologist, 33, 73-86. 
Zimmerman, B. J. (2000). Attaining self-regulation: A social cognitive perspective. In M.

Boekaerts, P. R. Pintrich, \& M. Zeidner (Eds.), Handbook of self-regulation (pp. 13-39). San Diego, CA: Academic Press.

Zimmerman, B. J. (2002). Becoming a self-regulated learner: An overview. Theory into Practice, 41(2), 64-70.

Zimmerman, B. J. (2006). Development and adaptation of expertise: The role of self-regulatory processes and beliefs. In K. A. Ericsson, N. Charness, P. J. Feltovich, \& R. R. Hoffman (Eds.), The Cambridge handbook of expertise and expert performance: 705-722. New York: Cambridge University Press.

Zohar, A., \& Barzilai, S. (2013). A review of research on metacognition in science education: Current and future directions. Studies in Science Education, 49(2), 121-169.

Zohar, A., \& Peled, B. (2008). The effects of explicit teaching of metastrategic knowledge on low- and high-achieving students. Learning and Instruction, 18, 337-353. 


\section{Tables}

Table 1: Demographic information for interview participants.

\begin{tabular}{|c|c|c|c|c|}
\hline $\begin{array}{l}\text { Participant } \\
\text { (Pseudonym) }\end{array}$ & $\begin{array}{l}\text { Years of Teaching } \\
\text { Experience }\end{array}$ & Education Level & Gender & $\begin{array}{l}\text { Grade } \\
\text { Assignment }\end{array}$ \\
\hline Amanda & 24 & B.A., B.Ed. & Female & 5 \\
\hline David & 15 & B.Sc., B.Ed., M.Ed. & Male & $7 / 8$ \\
\hline Jacob & 3 & B.Sc., B.Ed., M.Ed. & Male & $\begin{array}{l}1 / 2,6 \text { (French } \\
\text { Immersion) }\end{array}$ \\
\hline Ben & 18 & M. Ed. & Male & $\mathrm{K}$ \\
\hline Anna & 12 & B.Sc. & Female & 7 \\
\hline
\end{tabular}


Table 2: Summary of themes and codes.

\begin{tabular}{|c|c|}
\hline Theme & Codes \\
\hline $\begin{array}{l}\text { Student reflection as a visible } \\
\text { component of metacognitive } \\
\text { thinking }\end{array}$ & $\begin{array}{l}\text {-Prompting reflection-student led } \\
\text {-Questioning-guided reflection } \\
\text {-Consolidate learning-prompted reflection } \\
\text {-Reflective thinking that is ongoing } \\
\text {-Reflective thinking as part of work process } \\
\text {-Reflective thinking that is pre-planned }\end{array}$ \\
\hline Assessment for teacher learning & $\begin{array}{l}\text {-Assessment for learning-anonymous feedback-across subjects } \\
\text {-Assessment for learning-feedback for teacher } \\
\text {-Assessment for learning-feedback for teacher-adjusting assignments } \\
\text {-Assessment for learning-feedback for teacher-surveys } \\
\text {-Assessment for learning-feedback-accommodating } \\
\text {-Assessment for learning-secret ballots } \\
\text {-Assessment for learning-teacher reflection } \\
\text {-Comfort level-flexible-modifying practices } \\
\text {-Assessment for learning-questioning-informal }\end{array}$ \\
\hline Assessment as learning techniques & $\begin{array}{l}\text {-Across strategies-peer assessment } \\
\text {-Across strategies-self-assessment } \\
\text {-Assessment as learning-check list-self-assessment } \\
\text {-Assessment as learning-reflection on final product } \\
\text {-Assessment as learning-student led conference-student conference } \\
\text {-Checklist-peer assessment-self-assessment } \\
\text {-Improved quality of work-peer assessment-self-assessment } \\
\text {-Learning goals-student awareness } \\
\text {-Portfolios-assessment as learning-prompted reflective thinking } \\
\text {-Rubric-self- assessment-peer-assessment } \\
\text {-Rubric-self-assessment-modified for specific skill }\end{array}$ \\
\hline Dialogic assessment & $\begin{array}{l}\text {-Self-assessment } \\
\text {-Peer-assessment } \\
\text {-Dialogue } \\
\text {-Ongoing Peer Feedback } \\
\text {-Peer teaching } \\
\text {-Assessing quality of questions }\end{array}$ \\
\hline $\begin{array}{l}\text { Defining success and helping } \\
\text { students understand what } \\
\text { constitutes successful work }\end{array}$ & $\begin{array}{l}\text {-Defining Success-Class Discussion } \\
\text {-Defining Success-Co Constructing } \\
\text {-Success criteria-co construction with students } \\
\text {-Success criteria-goal to provide individual copies } \\
\text {-Success criteria-increased student responsibility } \\
\text {-Success criteria-increased student engagement } \\
\text {-Success criteria-individual copies-monitor their learning } \\
\text {-Success criteria-learning goal } \\
\text {-Success criteria-students need prompting-expectation } \\
\text {-Success criteria-teacher constructed }\end{array}$ \\
\hline
\end{tabular}




\begin{tabular}{ll}
\hline & -Success criteria-teacher constructed-defining success \\
& -Success criteria-teacher constructed-student friendly language \\
& -Success criteria-visually available/prompts \\
& -Student engagement-develop criteria \\
\hline Professional development & -Knowing success in other classrooms \\
opportunities and sharing of & -Explicit training \\
relevant resources & -More training \\
\hline Concrete metacognitive and & -Need- More ideas \\
assessment resources & -Primary resources \\
& -Specific learning strategies \\
& -How to implement best practices \\
\hline
\end{tabular}

